\title{
Study Of The Stability Of Water-In-Oil Emulsion Intended for the Extraction of Heavy Metals Application: Copper Ions
} Saliha Bouranene $^{1 *}$, Ardjoune Amer Aouad ${ }^{1}$, Abdeldjalil Gouassmia' ${ }^{1)}$, Selma Djaber ${ }^{1,2)}$, Lotfi

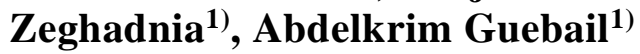

${ }^{1}$ )University of Mohamed Chérif Messaadia, Faculty of Sciences and Technology, Rue d'Annaba, BP 1553, 41000 Souk-Ahras, Algeria.

${ }^{2}$ Laboratory of Science and Technology of Water and Environment LST2E, Mohammed Chérif Messaadia University, Algeria.

\begin{abstract}
This work aims to optimize the parameters that affect the stability of a W/O emulsion to exploit it in the extraction of heavy metals contained in the liquid effluents. The study of the emulsion stability shows that; an emulsification time of 10 minutes, a surfactant concentration of Span80 equal to $3 \%(\mathrm{w} / \mathrm{w})$, an extractant concentration of Triethylamine $\mathrm{N}\left(\mathrm{CH}_{2} \mathrm{CH}_{3}\right)_{3}$ equal to $5 \%(\mathrm{w} / \mathrm{w})$, an internal phase concentration of phosphoric acid $\left(\mathrm{H}_{3} \mathrm{PO}_{4}\right)$ of $0.75 \mathrm{M}$, a volume ratio of membrane phase to internal phase of 1 , a volume ratio of external phase to the emulsion of 20 and a stirring speed of $180 \mathrm{rpm}$; lead to the formation of a very stable emulsion with a very low rupture rate of around $1.92 \%$ after one hour of contact time. The results of extraction of copper ions revealed that under the best operational conditions, the extraction yield was closed to $93.33 \%$ for $20 \%$ extractant content, a contact time of 12 minutes, and an initial concentration of copper ions of $400 \mathrm{ppm}$. The application of this new membrane matrix based on phosphoric acid used as inner phase, sorbitan monooleate as a surfactant, and Triethylamine as extractant has been proven effective for extracting copper ions in water. Paper type: Research paper
\end{abstract}

Keywords: Stability; emulsified liquid membrane; extraction; heavy metals; Copper ions.

Citation: Saliha Bouranene, Ardjoune Amer Aouad, Abdeldjalil Gouassmia, Selma Djaber, Lotfi Zeghadnia, Abdelkrim "Study Of The Stability Of Water-In-Oil Emulsion Intended for the Extraction Of Heavy Metals Application: Copper lons" Jordanian Journal of Engineering and Chemical Industries, Vol. 4, No.2, pp:62-69 (2021).

\section{Introduction}

The major problem encountered during the application of the emulsified liquid membrane technique is the stability of emulsion since the expulsion of the internal phase (receptor) to the external phase (to be treated) reduces the effectiveness of the emulsion extraction of the solute. The stability of the emulsion globules poses a crucial problem in implementing the liquid surfactant membrane on an industrial scale. The rupture of the membrane is the consequence of emulsion breakage, causing the expulsion of the internal phase towards the external phase. The emulsion stability is based on the formulation of the membrane, the method of preparation of the emulsion, and the conditions of the mixture of the emulsion with the external phase (Daas and Hamdaoui, 2010). The stability of the emulsion is the main obstacle to the implementation of the emulsion liquid membrane technique. It defines the ability of the liquid membrane to resist shear stresses. Several phenomena which cause emulsion breakage and which are mainly summarized in emulsion swelling, creaming, sedimentation, flocculation of droplets and coalescence (Chakraborty et al., 2010). Recent studies have revealed that emulsion stability is affected by Different parameters such as surfactant concentration, treatment ratio, the volume ratio of internal to membrane phase, and stirring speed (Ardehali et al., 2020; Rosly et al., 2020; Shamkhi et al., 2021; Shokri et al., 2020). The emulsion liquid membrane (ELM) stability was enhanced by adding a high molecular weight polymer to the membrane phase, namely polyisobutylene (PIB). The best working conditions found are a PIB concentration equal to $1.5 \%(\mathrm{w} / \mathrm{w})$, a surfactant concentration equal to $2 \%(\mathrm{w} / \mathrm{w})$, a stirring speed of the order of $300 \mathrm{rpm}$, a treatment ratio equal to $1: 10$, and a volume ratio of internal to membrane phase equal to 1:1. Under the mentioned conditions, the emulsion reached $0 \%$ of the swelling and $0.39 \%$ leakage (Ardehali et al., 2020).

* Corresponding author: E-mail:saliha.bouranene@yahoo.fr Received on May 21, 2021;

ORCID: https://orcid.org/0000-0003-1881-2632

Jordanian Journal of Engineering and Chemical Industries (JJECI), Vol.4, No.2, 2021, pp. 62-69. 
The study of the emulsion stability was made by controlling the size distribution of the droplets and the break-up time while simultaneously introducing into the membrane two kinds of surfactants, namely sorbitan monooleate (Span 80) and polyoxyethylene sorbitan monooleate (Tween 80). The results found were very satisfactory from the point of view of emulsion stability and lack of its swelling with a hydrophilic-lipophilic balance (HLB) of 5.3\% (w / v) obtained from the combination of Span 80 and Tween 80 (Rosly et al., 2020). On the other hand, the stability of the emulsion can be considerably improved by incorporating nanoparticles into the liquid membrane (Al-Obaidi et al., 2021; Shirasangi et al., 2020; Salman and Mohammed, 2019). It was found that the use of $\alpha$-Fe2O3 magnetic particles enhanced the stability of the emulsion, giving a lead ion extraction efficiency of 97.2\% (Salman and Mohammed, 2019). The rupture of emulsion is caused by a vigorous stirring and the inappropriate formulation of certain emulsion compounds (Laguel and Samar, 2019). The implementation of emulsified liquid membrane extraction requires an optimization of the two most important criteria, which are the emulsion stability during the transfer of targeted solute material from the external phase to the trapping phase via the membrane and the ability of the system to extract solutes contained in the aqueous solution to be treated (Samar et al., 1992). With this in mind, the effect of several parameters was studied, and some extraction tests on synthetic solutions of copper sulfate were carried out. To the best of our knowledge, no matrix composition similar to our emulsion has been used in the literature.

\section{Materials and Methods}

\subsection{Methodology}

The organic phase (membrane) chosen consists of adequate amounts of surfactant Span80) and extractant (Triethylamine, TEA or Tributyl phosphate, TBP) dissolved in a diluent (hexane, heptane, or kerosene). The membrane constituents are mixed with moderate stirring using a magnetic bar for 5 minutes to obtain a homogeneous solution. The internal aqueous phase is an acidic solution of $\mathrm{H}_{2} \mathrm{SO}_{4}$, $\mathrm{H}_{3} \mathrm{PO}_{4}$, or $\mathrm{HCl}$. The W/O emulsion was obtained by emulsifying a volume of the organic phase with an equal volume of the internal phase using a high-speed homogenizer of the BOSCH type (No MSM6250) for a fixed time. The stability of a liquid membrane is one of the most severe factors influencing solute removal. In our study, the tracer method was used to monitor the emulsion stability. The method introduces the internal phase, a tracer that can neither diffuse through the membrane nor be transported by the extractant. The possible presence of this tracer in the external phase is thus proof of a partial break of the emulsion during contact between it and the external aqueous phase. The outer water phase is distilled acid-free water. Thus the change in the acidity of this will reflect the break of emulsion. Stirring of the external phase is provided by a test jar propeller (Lovibond model). The rupture rate BR (\%) represents the percentage of expelled volume from the internal phase to the external phase $V_{r}$ relative to the initial volume of the internal phase $V_{\text {int }}$, eq. (1). The volume $V_{r}$ is determined from a material balance by measuring the initial acidity of the external phase and the variation of its acidity as a function of time after contact with the emulsion, eq. (2):

$$
\begin{gathered}
B R(\%)=\frac{V_{r}}{V_{\text {int }}} \times 100 \\
V_{r}=\frac{V_{0 \operatorname{ext}}\left(10^{-p H 0}-10^{-p H}\right)}{\left(10^{-p H 0}-\left[H^{+}\right]_{i}\right)}
\end{gathered}
$$

Where $\mathrm{V}_{0 \mathrm{ext}}$ is the initial external phase volume, $\mathrm{pH}_{0}$ is the $\mathrm{pH}$ of the initial external phase, and $\mathrm{pH}$ is the $\mathrm{pH}$ of the external $\mathrm{phase}$ as a function of time of agitation, and $\left[\mathrm{H}^{+}\right]_{\mathrm{i}}$ the protons initial concentration in the internal phase (Bouranene et al., 2003).

\section{Results and Discussion}

\subsection{Optimization of the stability parameters of water-in-oil emulsion 2.1.1 Effect of surfactant concentration}

In an emulsified liquid membrane system, the content of surfactant added as an emulsifying agent influences the stability of the emulsion. The surfactant concentration was in the range of $1-5 \%(\mathrm{w} / \mathrm{w})$. The $\mathrm{pH}$ of the external phase was measured every $2 \mathrm{~min}$. The change in the $\mathrm{pH}$ of this phase over time is an indication of the emulsion breakage. Emulsification time $=10$ min; Concentration of $\mathrm{TEA}=5 \%(\mathrm{w} / \mathrm{w}) ;$ Internal phase $[\mathrm{HCl}]=0.75 \mathrm{M} ;$ Diluent=Hexane; $V_{\text {memb }} / V_{\text {int }}=15 / 15 ; \quad V_{\text {ex }} / V_{\text {em }}=20 ;$ Stirring speed=180 rpm; Temperature $=18 \pm 2{ }^{\circ} \mathrm{C}$. Figure 1 shows that the break rate (BR\%) decreases for a concentration varying from 1 to $3 \%$ (w/w)of Span 80 and increases after that. The surfactant forms a protective wall between the outer and inner phases, preventing water leakage. For concentrations less than $3 \%$, the emulsion is fragile, and the amount of surfactant is insufficient to surround the entire internal aqueous phase. Moreover, it is well recognized that the increase in the surfactant concentration leads to an increase in the viscosity of the W/O emulsion, which slows down the extraction kinetics (Goodarzi and Zendehboudi, 2019). Increasing the surfactant content beyond 3\% $(\mathrm{w} / \mathrm{w})$ reduces the stability of the emulsion. A concentration of $3 \%(\mathrm{w} / \mathrm{w})$ leads to a slight break $(\mathrm{BR}=2.86 \%$ for a contact time of $60 \mathrm{~min})$. 


\subsubsection{Effect of emulsification time}

The influence of this time on the stability of the emulsion is shown in Figure 2. For an insufficient emulsification time (4 min and $7 \mathrm{~min}$ ), the rupture of the organic phase is significant because the shear of the internal phase is less important, which causes droplets large enough that can coalesce quickly. For a very long emulsification time (12 $\mathrm{min})$, the rupture of the organic phase is also high because the cutting of the internal phase causes a large number of droplets. The distance between these droplets becomes very small, which facilitates their coalescence and expulsion from the internal aqueous phase to the external aqueous phase (Bouranene et al., 2003). The optimum value of the emulsification time is 10 minutes.

\subsubsection{Effect of extractant concentration}

The choice of carrier or extractant is a decisive criterion in emulsified liquid membrane (ELM) extraction since it must form a complex with the metal (Zabat, 2017). To investigate the effect of carrier concentration, the concentration of Triethylamine (TEA) was varied in the range of 4 to $7 \%$ (w/w) by weight (Figure 3). As can be seen, the increase of the extractant concentration is unfavorable for the emulsion stability. This behavior can be ascribed to Triethylamine's interfacial properties, which reduces the stability of the emulsion, which causes the ejection of the inner phase to the external phase, thus increasing the rate of rupture. An extractant concentration equal to $5 \%$ (w/w) was chosen for a reason of stability.

\subsubsection{Effect of internal phase concentration}

The effect of the concentration of the internal phase on the stability of the emulsion is illustrated in

Figure 4. The concentration values taken are: $0.5 \mathrm{M}, 0.75 \mathrm{M}$ and $1 \mathrm{M}$. These results show that the increase of acid concentration in the internal phase leads to the destabilization of the emulsion, which is in agreement with work done by other researchers (Bouranene et al., 2003; Bahloul et al.,

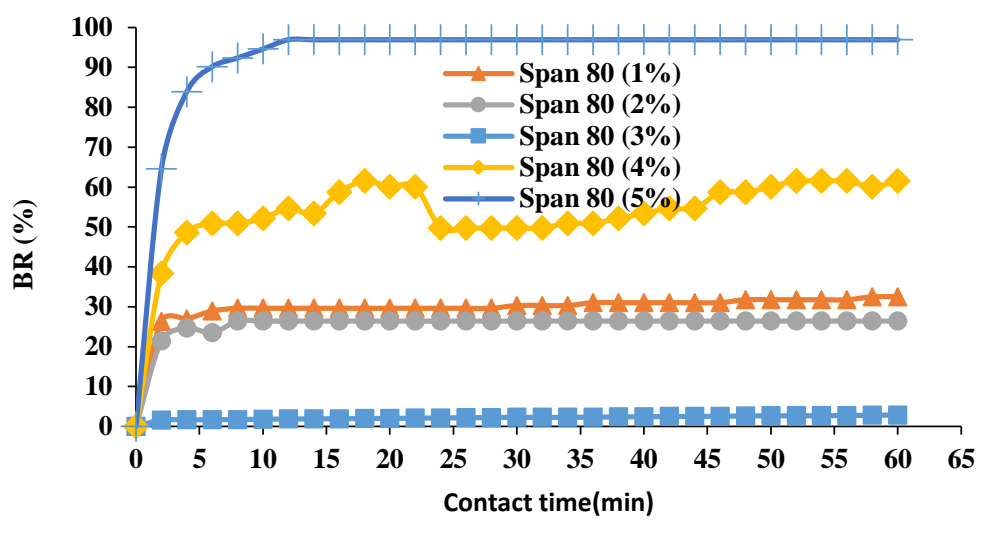

Fig. 1 Effect of Span 80 concentration on the stability of W/O emulsion.

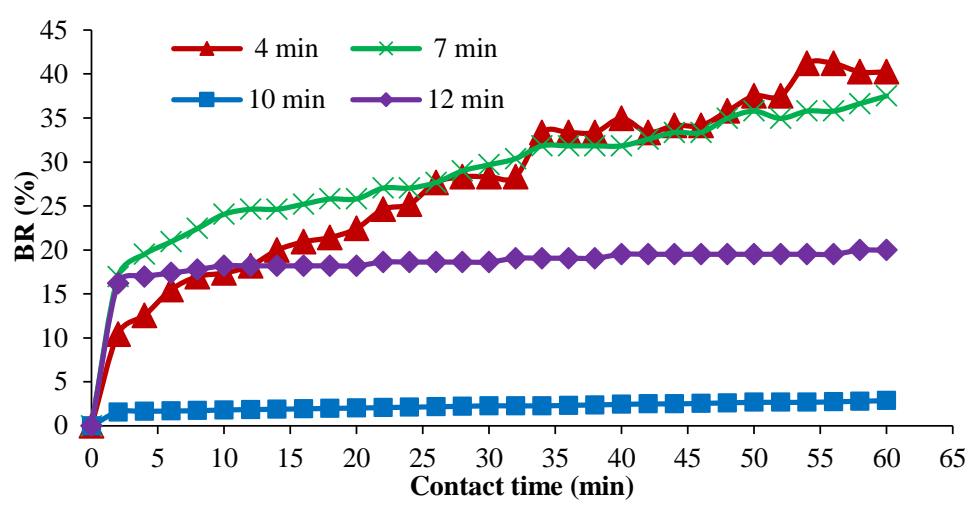

Fig. 2 Effect of the emulsification time on the stability of W/O emulsion. Concentration of Span $80=3 \%(\mathrm{w} / \mathrm{w})$; Concentration of TEA $=5 \%(\mathrm{w} / \mathrm{w})$; Internal phase $[\mathrm{HCl}]=0.75 \mathrm{M} ;$ Diluent=Hexane; $V_{\text {memb }} / V_{\text {int }}=15 / 15 ; \mathrm{V}_{\text {ext }} / \mathrm{V}_{\mathrm{em}}=20 ;$ Stirring speed $=180 \mathrm{rpm}$; Temperature $=8 \pm 2^{\circ} \mathrm{C}$.

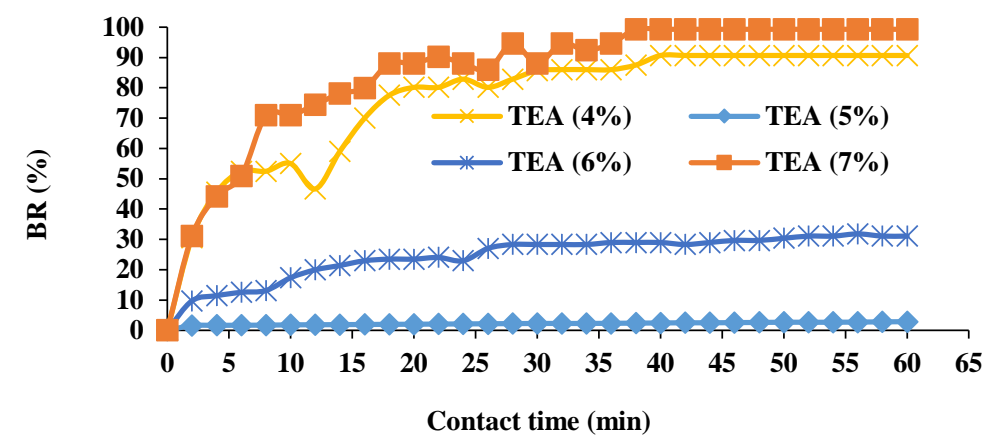

Fig. 3 Effect of extractant concentration (TEA) on the stability of W/O emulsion. Emulsification time $=10 \mathrm{~min}$; Concentration of Span $80=3 \%$; Internal phase $[\mathrm{HCl}]=0.75 \mathrm{M}$; Diluent=Hexane; $V_{m e m b} / V_{\text {int }}=15 / 15 ; V_{e x t} / V_{e m}=20$; Stirring speed=180 rpm; Temperature $=18 \pm 2^{\circ} \mathrm{C}$.

2013). The raising of the breakage rate can be explained by partial hydrolysis of the surfactant (Span80) catalyzed by protons. This reaction leads to reducing the surface-active properties of the surfactant (Belhaj et al., 2020). The best stability of W/O emulsion was obtained for an internal phase concentration of $0.75 \mathrm{M}$. 


\subsubsection{Effect of the nature of internal phase}

The nature of the internal phase has been varied because several purification solutions can be used in MLE systems (Bouranene et al., 2017). The selection of the purification phase (internal) is a critical factor in studying the stability of the emulsion. For this purpose, different acid purification solutions have been used in the ELM technique other than $\mathrm{HCl}$, sulfuric acid $\left(\mathrm{H}_{2} \mathrm{SO}_{4}\right)$, and phosphoric acid $\mathrm{H}_{3} \mathrm{PO}_{4}$. The results are shown in Figure 5. It is found that the breaking rate is the lowest where the phosphoric acid is used as an internal phase giving a value of $\mathrm{BR}=1.92 \%$ for a contact time of $60 \mathrm{~min}$. The $\mathrm{HCl}$ curve is slightly higher than that of phosphoric acid, while the use of sulfuric acid leads to enormous values of rupture rate (BR=52\% after $60 \mathrm{~min})$. This phenomenon can be attributed to the acid force, which expresses its dissociation capacity and gives up the $\mathrm{H}^{+}$protons. Since we are interested in emulsion stability, we have continued to work with phosphoric acid as a purification phase.

\subsubsection{Effect of the type of diluent}

The diluent has a significant function in the processes of the emulsified liquid membranes. The thickness and the permeability of the membrane strongly depend on two essential parameters, i.e., the viscosity and the density of the diluents (Kim et al., 1997). Three types of diluent, namely hexane, heptane, and kerosene, have been tested. The results obtained are shown

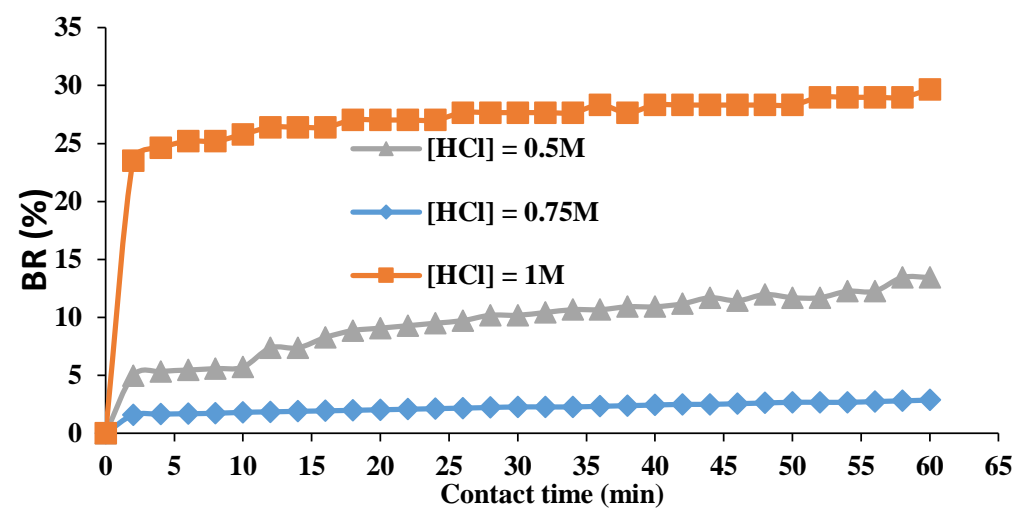

Fig. 5 Effect of the nature of internal phase on the stability of W/O emulsion. Emulsification time $=10 \mathrm{~min}$; Concentration of Span $80=3 \%(\mathrm{w} / \mathrm{w})$; Concentration of TEA $=5 \%(\mathrm{w} / \mathrm{w})$; Diluent=Hexane; Concentration of Internal phase $=0.75 \mathrm{M}$; Diluent=Hexane; $\mathrm{V}_{\mathrm{memb}} / \mathrm{V}_{\mathrm{int}}=15 / 15 ; \mathrm{V}_{\mathrm{ext}} / \mathrm{V}_{\mathrm{em}}=20$; Stirring speed $=180 \mathrm{rpm}$; Temperature $=18 \pm 2^{\circ} \mathrm{C}$.

in Figure 6. The lowest values of the rupture rate are obtained for kerosene. This result can be explained by the viscosity of kerosene, which is higher than that of hexane and heptane, increasing emulsion stability. So kerosene is considered a diluent of choice for the following tests.

\subsubsection{Effect of the volume ratio of membrane}

\section{phase to internal phase}

This volume ratio was varied: $15 / 10,15 / 15,15 / 20$, and $15 / 25$ (Figure 7). For the volume ratio (15/10), the excess in organic matter increases the viscosity and thickness of the membrane, increasing the emulsion globules' size and consequently reducing the interfacial area between the phase external and emulsion. However, when the volume fractions of the internal phase increase (15/20 and $15 / 25$ ratios), the rupture rates increase; this result is due to the ease expulsion of the internal phase to the external phase since its volume proportion is high in the emulsion (Sabry et al., 2007; Correia and Carvalho, 2003). Thus, a volume ratio $\left(V_{\text {memb }} / V_{\text {int }}\right)$ of $15 / 15$ was chosen as the best one

\subsubsection{Effect of the volume ratio of external phase to emulsion}

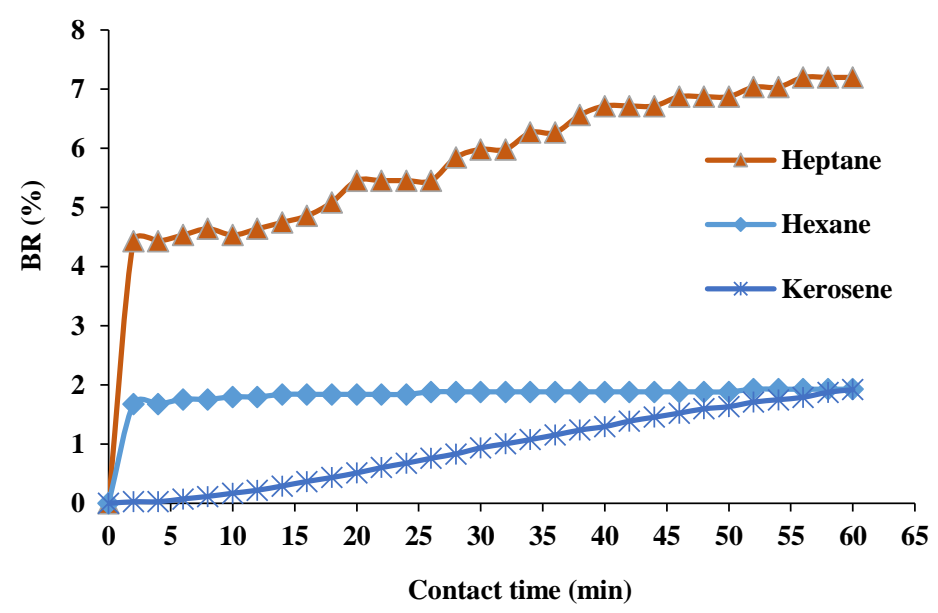

Fig. 6 Effect of the type of diluent on the stability of W/O emulsion. Emulsification time $=10 \mathrm{~min}$; Concentration of Span $80=3 \%(\mathrm{w} / \mathrm{w})$; Concentration of TEA $=5 \%$ $(\mathrm{w} / \mathrm{w})$; Internal phase $\left(\left[\mathrm{H}_{3} \mathrm{PO}_{4}\right]=0.75 \mathrm{M}\right) ; V_{\text {memb }} / V_{\text {int }}=15 / 15 ; V_{e x} / V_{e m}=20 ;$ Stirring speed $=180 \mathrm{rpm}$; Temperature $=8 \pm 2^{\circ} \mathrm{C}$.

According to the literature, this report is interested in emulsified liquid membrane extraction (Kulkarni et al., 2002). To examine its effect, it varied from 16 to 22 (Figure 8). It proceeded in the same way as the previous manipulations, for volume ratios of 16 to 18 , i.e., treatment ratios of 0.063 to 0.056 , the rupture rate of emulsion increases. This result can be explained by the phenomenon of swelling of the emulsion, which was noticed during the experiment (osmosis effect), leading to the membrane's embrittlement and consequently to its rupture. By going from a ratio $\left(V_{e x} / V_{e m}\right)$ of 20 to 22 (i.e. treatment ratios of 0.050 to 0.045 ), the breaking rate of the emulsion increases from $1.92 \%$ to $3.65 \%$ for a contact time of $60 \mathrm{~min}$. 
This result can also be attributed to the swelling effect of the emulsion observed during the experiment, leading us to deduce that certain proportionality must be respected between the volume of emulsion and that of the external phase (Bouranene et al., 2003). The optimal ratio maintained $\left(V_{e x t} / V_{e m}\right)$ to equal to 20 seems to be good.

\subsubsection{Effect of stirring speed}

The influence of stirring speed on the emulsion stability is given in Figure 9. The stirring speed of $180 \mathrm{rpm}$ generates the lowest breaking percentages. When the agitation level decreases $(<180 \mathrm{rpm})$, the created emulsion globules have a large size, resulting in a less critical material transfer. In other words, the emulsion dissolution is more distinct, and the leakage of the internal phase occurs. This can be explained by the increased osmotic swelling of the membrane (Goodarzi and Zendehboudi, 2019). By raising the stirring speed to more than $180 \mathrm{rpm}$, the stability of the emulsion has decreased. This can be explained by the fact that the high, stirring speed improves the dispersion of the globules emulsion in the phase to be treated, from which a large interfacial area of material transfer is obtained by the formation of small globules, which promotes the ejection of the internal phase to the external one (Bouranene et al., 2003).

\subsection{Extraction of copper ions by emulsified liquid membrane}

To test the efficiency of the membrane manufactured under the optimal conditions and whose stability is too high, we carried out two types of tests:

At first, we varied the concentration of copper ions in the external phase from $25 \mathrm{ppm}$ up to $400 \mathrm{ppm}$ (Figure 10).

The extraction yield of the copper ions was quantified as follows:

$$
R(\%)=\frac{C_{0 e x t} V_{0 \text { ext }}-C_{0 \text { exf }} V_{0 e x f}}{C_{0 \text { ext }} V_{0 \text { ext }}} \times 100
$$

Where:

$C_{\text {Oext }}$ : initial concentration of solute in the external phase;

$V_{\text {oext }}$ : initial volume of the external phase;

$C_{f e x t}$ : final concentration of the solute in the external phase;

$V_{\text {fext }}$ : final volume of the external phase.

It should be noted that copper ions were analyzed by complexation with EDTA at $\mathrm{pH}=10.0$ in the presence of murexide as an indicator. The extraction yields change according to the concentration, and the values found vary between $26.66 \%$ and $35.45 \%$ for a contact time equal to 6 minutes. This evolution can be explained by the increase of diffusion flux due to the increase of the concentration gradient between the external and the membrane. Secondly, we applied emulsified liquid membrane extraction to a solution containing 400 ppm

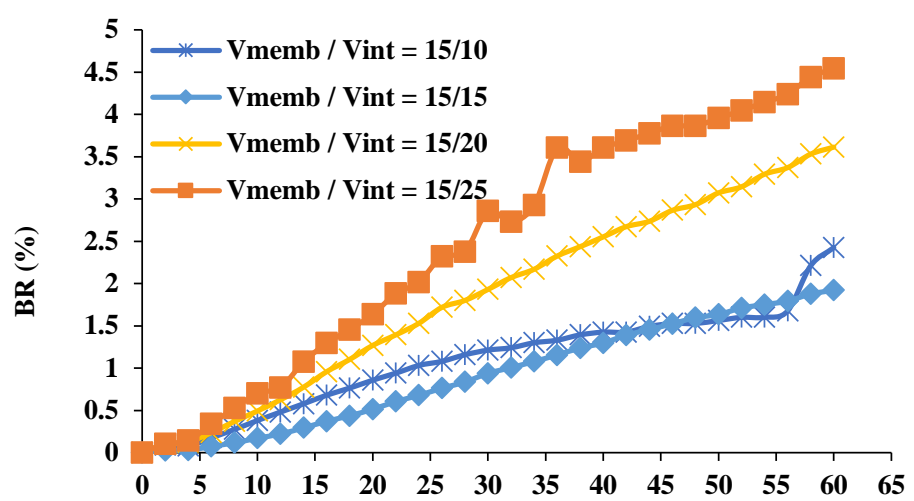

\section{Contact time (min)}

Fig. 7 Effect of the ratio $\left(\mathrm{V}_{\text {memb }} / \mathrm{V}_{\text {int }}\right)$ on the stability of W/O emulsion. Emulsification time $=10 \mathrm{~min}$; Concentration of Span $80=3 \%(\mathrm{w} / \mathrm{w})$; Concentration of TEA=5\% $(\mathrm{w} / \mathrm{w}) ;$ Diluent=kerosene; Internal phase $\left(\left[\mathrm{H}_{3} \mathrm{PO}_{4}\right]=0.75 \mathrm{M}\right) ; V_{\text {memb }} / V_{\text {int }}=15 / 15$; $V_{e x d} / V_{e m}=20$; Stirring speed $=180 \mathrm{rpm}$; Temperature $=8 \pm 2^{\circ} \mathrm{C}$.

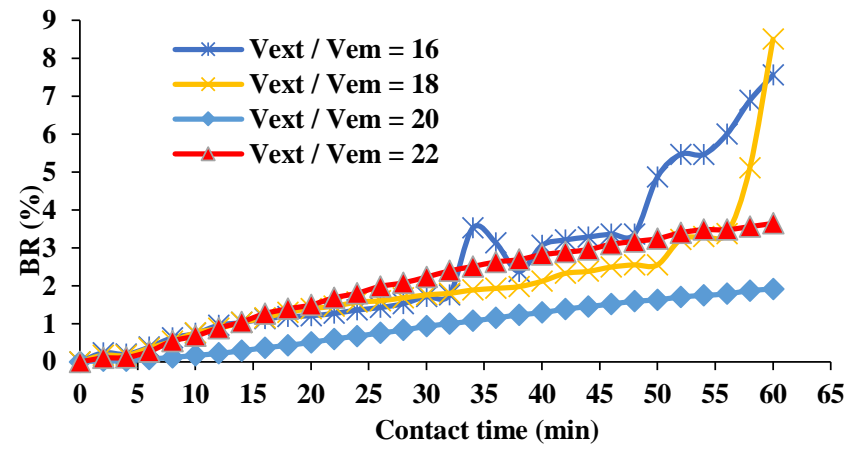

Fig. 8 Effect of the ratio $\left(\mathrm{V}_{\mathrm{ex}} / \mathrm{V}_{\mathrm{em}}\right)$ on the stability of W/O emulsion. Emulsification time $=10 \mathrm{~min}$; Concentration of $\operatorname{Span} 80=3 \%(\mathrm{w} / \mathrm{w}) ;$ Concentration of TEA $=5 \%$ $(\mathrm{w} / \mathrm{w})$; Diluent=kerosene; Internal phase $\left(\left[\mathrm{H}_{3} \mathrm{PO}_{4}\right]=0.75 \mathrm{M}\right) ; \mathrm{V}_{\mathrm{memb}} / \mathrm{V}_{\mathrm{int}}=15 / 15$; Stirring speed $=180 \mathrm{rpm}$; Temperature $=18 \pm 2{ }^{\circ} \mathrm{C}$..

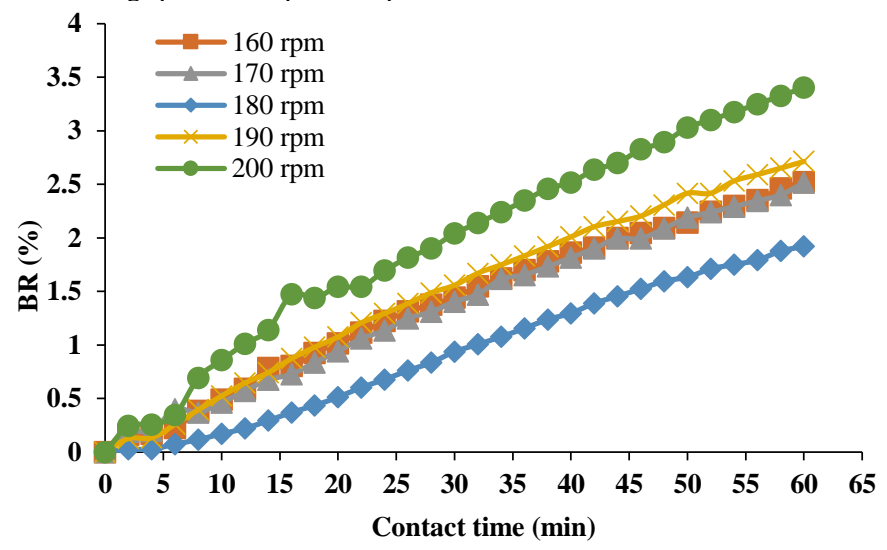

Fig. 9 Effect of the stirring speed on the stability of the W/O emulsion. Emulsification time $=10 \mathrm{~min}$; Concentration of Span $80=3 \%(\mathrm{w} / \mathrm{w})$; Concentration of TEA $=5 \%$ $(\mathrm{w} / \mathrm{w})$; Diluent $=$ kerosene; Internal phase $\left(\left[\mathrm{H}_{3} \mathrm{PO}_{4}\right]=0.75 \mathrm{M}\right) ; \mathrm{V}_{\mathrm{memb}} / \mathrm{V}_{\mathrm{int}}=15 / 15$; $\mathrm{V}_{\text {ext }} / \mathrm{V}_{\mathrm{em}}=20$; Temperature $=18 \pm 2^{\circ} \mathrm{C}$. 
copper ions, increasing the triethylamine content from 5 to $20 \%(\mathrm{w} / \mathrm{w})$ by weight but keeping the other entire parameters already optimized constantly. The tests were done for two contact times, 6 and 12 minutes (Figure 11).

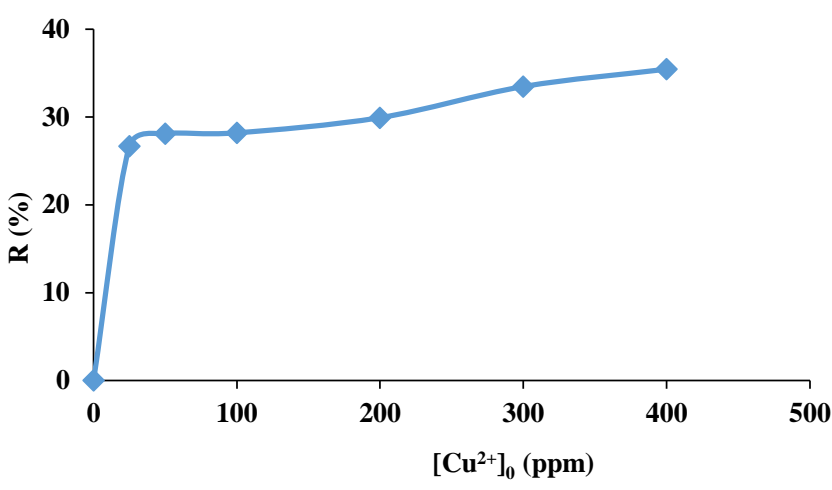

Fig. 10 Extraction efficiency versus initial concentration of copper ions. Extractant concentration $=5 \%(\mathrm{w} / \mathrm{w})$; Contact time $=6 \mathrm{~min}$

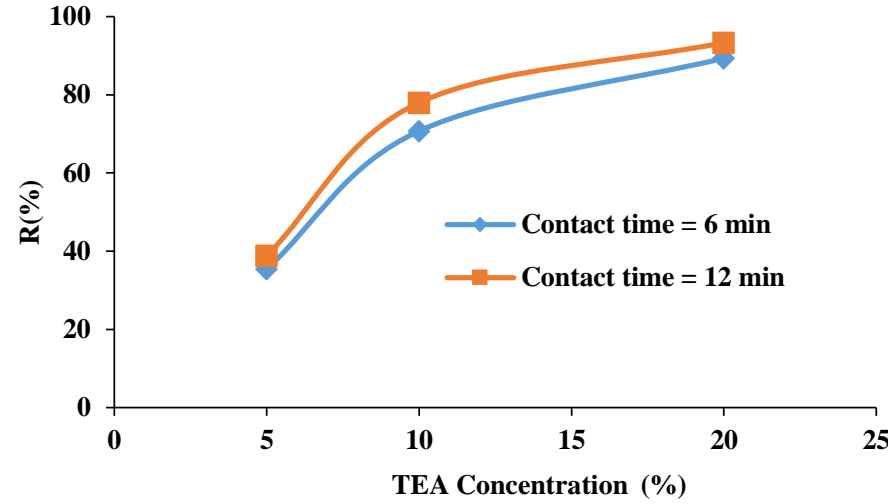

Fig. 11 Extraction efficiency versus extractant concentration. $\left[\mathrm{Cu}^{2+}\right]_{0}=400 \mathrm{ppm}$.

The kinetics of extraction improves as a function of the contact time and obviously by the elevation of the extractant concentration, which acts as a transporter whose mode of action is solvation and/or chelation. The process of solute transfer from the external phase to the internal phase occurs according to two interfacial reactions. The first reaction is the construction of the complex between the heavy metal $\left(\mathrm{Cu}^{2+}\right)$ ion and the carrier (TEA) at the level of the first interface; external phase/membrane, Eq. (4). At the same time, the second reaction is the release of the carrier at the second interface; membrane / internal phase, Eq. (5).

$$
\begin{aligned}
& \mathrm{C}_{6} \mathrm{H}_{15} \mathrm{~N}+\mathrm{Cu}^{2+} \leftrightarrow \mathrm{C}_{6} \mathrm{H}_{13} \mathrm{NCu}+2 \mathrm{H}^{+} \\
& \mathrm{C}_{6} \mathrm{H}_{13} \mathrm{NCu}+\mathrm{H}_{3} \mathrm{PO}_{4} \leftrightarrow \mathrm{C}_{6} \mathrm{H}_{15} \mathrm{~N}+\mathrm{CuHPO}_{4}
\end{aligned}
$$

The best yields are obtained at $20 \%$ TEA ( $\mathrm{R}=89.34 \%$ for a time of $6 \mathrm{~min}$ and $93.33 \%$ for $12 \mathrm{~min}$ ). This means that a high concentration of TEA at the interface between the emulsion and the external phase promotes solute transport. The same phenomenon was observed during the extraction of chromium $\left(\mathrm{Cr}^{6+}\right)$ ions by tributyl phosphate TBP is an emulsified liquid membrane extraction system [4]. The author produced a very stable emulsion with a $20 \%$ TBP content giving a rupture rate of the order of $0.3 \%$ (range of variation of the extractant contraction during the study of the emulsion stability is 20 to $30 \%$ ). The maximum yield attained by applying this emulsion to a solution charged with chromium ions is $61 \%$. Increasing the extractant content to values above $30 \%$ could increase the extraction yield to $100 \%$. However, it should not be abused in increasing the extractant content because it influences the stability of the emulsion.

\section{Conclusions}

The spirit relating to the problem of the polluting load present in aqueous media is structured around methodological and environmental questions. Indeed, as part of this work, the development of an advanced membrane technology to treat water contaminated by heavy metals is successfully applied. Emulsified liquid membrane extraction is a vigorous, reliable, and robust separation technique, based essentially on the manufacture of a stable emulsion whose stability depends on several factors. These optimal conditions have given us a very stable emulsion with a meager rupture rate of $1.92 \%$ after one hour of contact time. The application of this emulsion on copper ions-loaded solutions, chosen as model ions in our study, led to an excellent trapping efficiency ( $>90 \%)$ for an initial concentration of 400 ppm of copper ions and during high-speed extraction kinetics (12minutes). The extraction procedure is considered a type II system, prompted us to increase the trimethylamine content to levels higher $(20 \%)$. However, the complexity of the subject leaves the field open to further work in specific fields, such as the realization of emulsion demulsification to study the recycling of the membrane and the application of this extraction technique on industrial discharges.

\section{Acknowledgment}

The authors acknowledge the research grant provided by the Algerian Ministry of Higher Education and Scientific Research (project A16N01UN410120180002). 


\section{Nomenclature}

\begin{tabular}{|c|c|c|}
\hline $\mathrm{BR} \%$ & $=$ breaking rate & {$[-]$} \\
\hline $\mathrm{C}_{\text {0ext }}$ & $=$ initial concentration of solute in the external phase & {$[\mathrm{mol} / \mathrm{L}]$} \\
\hline $\mathrm{C}_{\text {fext }}$ & $=$ final concentration of the solute in the external phase & {$[\mathrm{mol} / \mathrm{L}]$} \\
\hline $\mathrm{Cr}^{6+}$ & $=$ Chromium VI & {$[\mathrm{mol} / \mathrm{L}]$} \\
\hline ELM & $=$ Emulsified Liquid Membrane & {$[-]$} \\
\hline EDTA & $=$ Ethylenediaminetetraacetic & {$[-]$} \\
\hline $\begin{array}{l}{\left[\mathrm{H}^{+}\right]_{\mathrm{I}}} \\
\mathrm{HCl}\end{array}$ & $\begin{array}{l}=\text { the protons initial concentration in the internal phase } \\
=\text { hydrochloric acid }\end{array}$ & $\begin{array}{l}{[\mathrm{mol} / \mathrm{L}]} \\
{[-]}\end{array}$ \\
\hline $\mathrm{H}_{3} \mathrm{PO}_{4}$ & $=$ phosphoric acid & {$[-]$} \\
\hline $\mathrm{H}_{2} \mathrm{SO}_{4}$ & $=$ sulfuric acid & {$[-]$} \\
\hline $\mathrm{pH}_{0}$ & $=\mathrm{pH}$ of the initial external phase & {$[-]$} \\
\hline $\mathrm{pH}$ & $=\mathrm{pH}$ of the external phase as a function of time of agitation & [-] \\
\hline $\mathrm{R} \%$ & $=$ extraction yield perecntage & [\%] \\
\hline Span80 & $=$ Sorbitan monooleate & {$[-]$} \\
\hline TBP & $=$ Tributyl Phosphate & {$[-]$} \\
\hline TEA & $=$ Trimethylamine & {$[-]$} \\
\hline $\mathrm{V}_{\mathrm{em}}$ & $=$ volume of the emulsion phase & {$[\mathrm{mL}]$} \\
\hline $\mathrm{V}_{\mathrm{ext}}$ & $=$ volume of the external phase & {$[\mathrm{mL}]$} \\
\hline $\mathrm{V}_{\text {int }}$ & $=$ initial volume of the internal phase & {$[\mathrm{mL}]$} \\
\hline $\mathrm{V}_{\mathrm{memb}}$ & $=$ volume of the membrane & {$[\mathrm{mL}]$} \\
\hline $\mathrm{V}_{\mathrm{r}}$ & $=$ volume expelled from the internal phase by rupture & {$[\mathrm{mL}]$} \\
\hline $\mathrm{V}_{\text {0ext }}$ & $=$ initial volume of the external phase & {$[\mathrm{mL}]$} \\
\hline$V_{\text {fext }}$ & $=$ final volume of the external phase & {$[\mathrm{mL}]$} \\
\hline $\mathrm{W} / \mathrm{O}$ & $=$ water in oil emulsion & {$[-]$} \\
\hline $\mathrm{w} / \mathrm{w}$ & =weight in weight & {$[\mathrm{g} / \mathrm{g}]$} \\
\hline
\end{tabular}

\section{References}

Al-Obaidi, Q., Malak Alabdulmuhsin, M., Tolstik, A., Trautman, J.G., and M., Al-Dahhan "Removal of hydrocarbons of 4-Nitrophenol by emulsion liquid membrane (ELM) using magnetic $\mathrm{Fe}_{2} \mathrm{O}_{3}$ nanoparticles and ionic liquid", J. Water. Process. Eng., 39, 101729 (2021).

Ardehali, B.A., Zaheri, P., and T., Yousefi "The effect of operational conditions on the stability and efficiency of an emulsion liquid membrane system for removal of uranium", Prog. Nucl. Energy., 130, 103532 (2020).

Bahloul, L., Ismail, F., and M. H., Samar "Extraction and Desextraction of a Cationic Dye using an Emulsified Liquid Membrane in an Aqueous Solution", Energy Procedia., 36, 1232-1240 (2013).

Belhaj, A. F., Elraies, K. A., Mahmood, S. M., Zulkifi, N. N., Akbari, S., and O. S, Hussie " The effect of surfactant concentration, salinity, temperature, and pH on surfactant adsorption for chemical enhanced oil recovery: a review", J. Pet. Explor. Prod. Technol., 10, 125-137 (2020).

Bouranene, S., Samar, M. H., and A., Abbaci "Extraction of cobalt and lead from waste water using a liquid surfactant membrane emulsion", Acta. Chimica. Slov., 50, 663-675 (2003).

Bouranene, S., Soualmia, A., Fievet, P., Déon,S., and F., Ismail "Extraction of ethanol from aqueous solutions by emulsion liquid membrane: optimization of operating conditions and influence of salts in the feed phase", Desalination. Water. Treat., 88, 106-115 (2017).

Chakraborty, M., Bhattacharya, C., and S., Datta "Emulsion liquid membranes: Definitions and classification, theories, module design, applications, new directions and perspectives", $1^{\text {st }}$, Edn., Elsevier (2010).

Correia, P., and J., Carvalho "Recovery of phenol from phenolic resin plant effluents by emulsion liquid membranes", J. Membr. Sci., 225, 41-49 (2003).

Dâas, A., and O., Hamdaoui "Extraction of bisphenol A from aqueous solutions by emulsion liquid membrane", J. Membr. Sci., 348, 360-368 (2010).

Goodarzi, F., and S., Zendehboudi "A Comprehensive Review on Emulsions and Emulsion Stability in Chemical and Energy Industries", Can. Soc. Chem. Eng., 97, 281-309 (2019).

Kim, S. J., Kim, S. C., and J., Kawasaki "Separation of Hydrocarbons by Liquid Surfactant Membrane with a Batch Stirred Vessel", Separ. Sci. Tech., 32, 12091221 (1997)

Kulkarni, P. S., Mukhopadhyay, S., Bellary, M. P., and S. K., Ghosh, "Studies on membrane stability and recovery of uranium (VI) from aqueous solutions using a liquid emulsion membrane process", Hydrometallurgy., 64, 49-58 (2002).

Laguel, S., and M. H., Samar "Removal of Europium(III) from water by emulsion liquid membrane using Cyanex 302 as a carrier", Desalination Water Treat., 165, 269-280 (2019).

Rai, P., Mishra, R., and S., Parihar "Quantifying the cement air pollution related human health diseases in Maihar City, MP, India", Res. J. of Recent Sci., 2, 229-233 (2013).

Rosly, M. B., Jusoh, N., Othman, N., Rahman, H. A., Sulaimana, R. N. R., and N. F. M., Noah "Stability of emulsion liquid membrane using bifunctional diluent and blended surfactant for phenol removal", Chem. Eng. Process., 148, 107790 (2020).

Sabry, R., Hafez, A., Khedr, M., and A., El-Hassanin "A Removal of lead by an emulsion liquid membrane Part I", Desalination., 212, 165-175 (2007).

Salman, H. M., and A. A., Mohammed "Extraction of lead ions from aqueous solution by costabilization mechanisms of magnetic $\mathrm{Fe}_{2} \mathrm{O}_{3}$ particles and nonionic surfactants in emulsion liquid membrane", Colloids Surfaces A Physicochem. Eng. Asp., 568, 301-310 (2019).

Samar, M. H., Pareau, D., Chesne, A., and G., Durand "Membranes liquides échangeuses de cations : application à l'extraction du nickel", Bull. Soc. Chim. Fr., 129, 259-264 (1992). 
Zabat, N. "Removal of lead by complexation using a heteropolyanion and extraction of formed complex by emulsified liquid membrane", J. Environ. Chem. Eng., 5, 2018-2023 (2017).

Shamkhi, H. A., Albdiri, A. D. Z., Jabir, F. A., and D., Petruzzelli "Removal of $\mathrm{Pb}^{2+}, \mathrm{Cu}^{2+}$, and $\mathrm{Cd}^{2+}$ Ions from a Saline Wastewater Using Emulsion Liquid Membrane: Applying Response Surface Methodology for Optimization and Data Analysis", Arab. J. Sci. Eng., (2021) https://doi.org/10.1007/s13369$\underline{021-05624-5}$.

Shokri, A., Daraei, P., and S., Zereshki "Water decolorization using waste cooking oil: An optimized green emulsion liquid membrane by RSM", J. Water. Process. Eng., 33, 101021 (2020).

Shirasangi, R., Kohli, H. P., Gupta, S., and M., Chakraborty "Separation of Methylparaben by emulsion liquid membrane: Optimization, characterization, stability and multiple cycles studies", Colloids. Surf. A., 597, 124761 